\title{
Numerical investigation of the optimum wind turbine sitting for domestic flat roofs
}

\author{
Salman Muhammad Ishfaq and Hassam Nasarullah Chaudhry* \\ School of Energy, Geoscience, Infrastructure and Society, Heriot-Watt University, P.O. Box: 294 345, Dubai, United Arab \\ Emirates
}

Received: 28 January 2018 / Accepted: 11 March 2018

\begin{abstract}
The power capacity of roof mounted wind turbines is dependent on several factors which influence its energy yield. In this paper, an investigation has been carried out using Computational Fluid Dynamics (CFD) to determine flow distribution and establish an optimum mounting location for a small wind turbine on a domestic flat roof. The realisable $k-\varepsilon$ and SST $k$ - $\omega$ turbulence models were compared to establish their consistency with one another with respect to the physical domain. Nine mounting locations were considered for a pole mounted wind turbine. Three windward positions on the upwind side of the flat surfaced building were considered as viable locations for mounting the small wind turbine. Out of the three windward locations, the central upwind $(1,0)$ mounting position was seen to be producing the highest velocity of $5.3 \mathrm{~m} / \mathrm{s}$ from the available ambient velocity which was $4 \mathrm{~m} / \mathrm{s}$. Therefore, this mounting location provided the highest extractable power for the wind turbine. Conclusively, wind properties along with the mounting locations can play a significant role in either enhancing or diminishing the small wind turbine's performance on a domestic flat roof.
\end{abstract}

Keywords: Betz limit / CFD / roof mounted / turbulence / wind turbine

\section{Introduction}

The need for more energy is growing rapidly around the world. Both developed and developing countries are growing at a fast pace with which more energy needs to be provided to supplement their progress. For about three centuries, the infamous non-renewable energy has been exploited to the extent at which the world has realised that an alternative source of energy must be utilised for the upcoming future. Many renewable sources of energy such as solar, wind, nuclear, geothermal and hydro are coming into play due to the awareness that non-renewable sources of energy will eventually deplete one day.

Wind power is one of the major renewable energy sources being considered for the foreseeable future. Many countries have employed the use of large on-shore and offshore wind farms which generate electricity with megawatt capacities. These wind farms tend to have several largescale wind turbines. Each large-scale wind turbine has the rated power of at least one megawatt [1]. Although the wind turbines can produce large sums of power, they do have several advantages as well as disadvantages. The major advantage of using wind power is that it is a clean source of energy. It uses the incoming wind as a source for

\footnotetext{
* e-mail: H.N.Chaudhry@hw.ac.uk
}

rotating the turbine's blades to produce electricity. A major disadvantage of using wind power is the availability of the energy itself. Wind is not consistent and changes continuously throughout. Thus, there is also further debate on whether wind power can be utilised as a centralised source for providing energy.

Small-scale wind turbines are mostly used in domestic houses for electricity generation. Many small-scale turbines provide a range of rated power. The rated power for these turbines is anywhere below 50 kilowatts [1]. The higher the rated power of a turbine, the larger the wind velocity is required to rotate its rotors for maximum output. Small wind turbines have been criticized for their lack of operational efficiency and consistency. Although small wind turbines are clean sources of energy generation, they tend to have several disadvantages which have made them very unpopular in the domestic market. Many decentralised energy generation techniques are criticised for not being able to provide the required powering capacity.

There are many reasons why small wind turbines are not able to perform to the required power capacity. These include incorrect capacity sizing of the wind turbine. The mounting locations in the area with respective to the incoming wind speed is another reason. Various wind turbines have specific cut-in speeds from which they start generating electricity. Wind turbines should be selected on 
the bases of available wind data. Placement of wind turbines is another mistake committed by users which influences their performance. Such issues require a more detailed analysis to fully understand and evaluate them.

Using Computational Fluid Dynamics (CFD), this work has adopted the use of a commercial small-scale roof mounted wind turbine to investigate various roof-mounted sitting positions for extracting maximum wind energy. The study was carried out by examining flow profiles, wind augmentations and power extraction. The parameters studied for implementation of a roof mounted small-scale wind turbine were the supply stream acceleration velocities along with the turbulence intensities.

\section{Previous related work}

Analysis of positioning small-scale wind turbines integrated in domestic buildings have been scarcely done. Although there is a significant amount of information about smallscale wind turbines, not much exists regarding where the turbines need to be positioned on domestic building roofs.

Tummala et al. [1], gave a generic review of everything that related regarding small-scale wind turbines. Wind turbines were referred as viable sources of energy production for the future. Wind turbines were shown to be categorized as large-scale and small-scale. Large-scale wind turbines have a larger power rating with also a larger rotor diameter. Small-scale wind turbines in turn have smaller power rating and smaller rotor diameters. Smallscale wind turbines were categorized by vertical-axis and horizontal-axis wind turbines. It was established that mounting a small-scale wind turbine on any roof needed consideration of the available wind data, roof shape profile and turbulence distribution.

Ledo et al. [2] conducted CFD simulations on three different roof profile shapes for understanding the wind velocity flow and turbulence intensity. The experiment was conducted for a set of urban houses of similar roof profile shapes that included a flat, pitched and pyramid roof. The simulations were conducted by using the SST $k-\omega$ turbulence model. The turbulence model was referred to be superior to the $k-\varepsilon$ turbulence model since it tends to over predict the eddy-viscosity in separated flow simulations. It was recommended that on flat roofs the wind turbine could be mounted on either the edge, corner or the center. It was noted that the location where there was a high turbulence level would be unsuitable for placing a wind turbine as design conditions state it to be not more than $16-18 \%$. This meant that the high turbulence level would reduce the life span of the wind turbine. It was noted that flat roof houses did not depend on the wind direction and mounting site for a speedup effect. It was also shown that the available wind power above the flat roof was consistently much higher than any other roof profile. It was concluded that flat roofs were better than the pitched and pyramid roof profiles as they produced the required parameters needed to mount a small-scale roof mounted wind turbine.

Abohela et al. [3] conducted CFD simulations for assessing the optimum seating positions of a small-scale roof mounted wind turbine on several roof profiles. The various roof profiles that were simulated included a flat, vaulted, domed, wedged, gabled and barrel. The model consisting of a flat roof had dimensions of 6 by $6 \mathrm{~m}$ and a height of $6 \mathrm{~m}$. It was also mentioned that the realisable $k-\varepsilon$ turbulence model was a much preferable method to use for evaluating flows around isolated buildings. When the wind flowed parallel to the building, the best seating position for the small-scale wind turbine was on a flat roof with coordinates $\mathrm{C} 2-3$ at height $1.45 \mathrm{H}$. When the wind direction was flowing at $45^{\circ}$, the best mounting position for the small-scale roof mounted wind turbine on the flat roof was with coordinates C2-2 at height $1.30 \mathrm{H}$. It was concluded that appropriate positioning of a small-scale roof mounted wind turbine could be viable when considering the air acceleration produced via a given roof profile.

Mertens [4] examined the parameters that effected small-scale roof mounted wind turbines. Flow features of an urban landscape were inspected for applying a roof mounted wind turbine. Primary parameters that were discussed included the desirable height above the roof as well as the variance of wind speed above the roof. Wind velocity on roof tops were determined by the skew and yaw angles of wind. These angles determine the separation bubble in which there is a lower velocity but also higher turbulence. The separation bubble was noted to be the region where velocity was at its lowest while turbulence would be at its highest. The high turbulence tends to damage the wind turbine by causing fatigue which results in a decrease in power output. Hence it is strongly recommended to site the wind turbine above the separation bubble on the roof. It was determined that the central mounting position had the highest energy density. The central mounting location was a preferable position for HAWT as the skew flow angles will be lesser.

Bukala et al. [5] investigated the parameters which influenced the efficiency of small-scale wind turbines. An overview of power generation from a wind turbine was provided. Equation (1) explains the parameters involved in energy obtained from a wind turbine. The parameters include air density $(\rho)$, wind turbine rotor swept area (A), and wind velocity $(u)$. The Betz limit which is the maximum efficiency of converting kinetic energy to mechanical power for a HAWT is $59.3 \%$. Final efficiencies of wind turbines are further reduced due to mechanical and electrical losses. Turbulent wind flow also decreases the performance efficiency of the wind turbine as it causes the recoverable kinetic energy of the wind to convert into turbulence flow. The turbulent or separation bubble is a region where the wind turbulence is maximum. Placement of a wind turbine in this region drastically reduces the energy output from it and inputs more dynamic loads which could further increase the maintenance and cost of operation. Another feature that can have both a positive and negative effect is the use of terrain acceleration effect. This can increase the wind velocity generated for the wind turbine but can also significantly increase the turbulence. It was concluded that the optimization of the wind turbines aerodynamics 


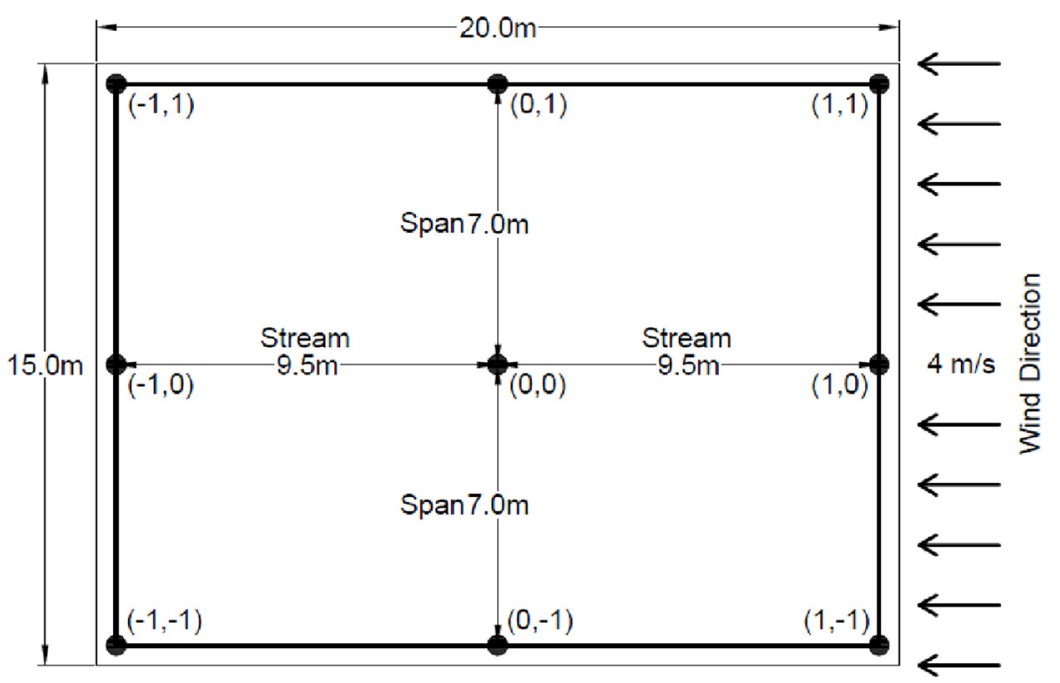

Fig. 1. Mounting locations for wind turbine.

had little effect on the efficiency of power production.

$$
P=\frac{\rho A u^{3}}{2}
$$

Cable [6] evaluated different turbulence models for forced and natural convective flow in the Atrium of the EV building. Several turbulence models were employed to validate their consistency with one another. All three of the $k$ - $\varepsilon$ turbulence models were employed which included the standard, Re-Normalisation Group (RNG) and the realisable. The realisable $k-\varepsilon$ turbulence model was noted to be superior to its counter parts due to it being able to predict separated flows and other complex secondary flow features. The realisable $k-\varepsilon$ turbulence model is composed of Equation (2) and Equation (3). The two $k-\omega$ turbulence models were also used that include the standard and ShearStress Transport (SST). The SST $k-\omega$ turbulence model is a combination of the standard $k-\omega$ and a transformed $k-\varepsilon$. Larger variety of different flows can be more precisely predicted by the SST $k-\omega$ turbulence model. The SST $k-\omega$ turbulence model is composed of Equation (4) and Equation (5).

$$
\begin{aligned}
\frac{\partial}{\partial t}(\rho k)+\frac{\partial}{\partial x_{j}}\left(\rho k u_{j}\right) & =\frac{\partial}{\partial x_{j}}\left[\left(\mu+\frac{\mu_{t}}{\sigma_{k}}\right)+\frac{\partial k}{\partial x_{j}}\right]+G_{k} \\
& +G_{b}-\rho-Y_{M}+S_{k} \\
\frac{\partial}{\partial t}(\rho)+\frac{\partial}{\partial x_{j}}\left(\rho u_{j}\right)= & \frac{\partial}{\partial x_{j}}\left[\left(\mu+\frac{\mu_{t}}{\sigma}\right)+\frac{\partial}{\partial x_{j}}\right]+\rho C_{1} S \\
-\rho C_{2} \frac{2}{k+\sqrt{v}}+C_{1} \frac{C_{3} G_{b}+S}{k} & \\
\frac{\partial}{\partial t}(\rho k)+\frac{\partial}{\partial x_{i}}\left(\rho k u_{i}\right) & =\frac{\partial}{\partial x_{j}}\left[\left(\mu+\frac{\mu_{t}}{\sigma_{k}}\right) \frac{\partial k}{\partial x_{j}}\right]+G_{k} \\
& -Y_{k}+S_{k}
\end{aligned}
$$

$$
\begin{aligned}
\frac{\partial}{\partial t}(\rho \omega)+\frac{\partial}{\partial x_{i}}\left(\rho \omega u_{i}\right) & =\frac{\partial}{\partial x_{j}}\left[\left(\mu+\frac{\mu_{t}}{\omega}\right) \frac{\partial k}{\partial x_{j}}\right]+G_{\omega} \\
& -Y_{\omega}+S_{\omega}+D_{\omega}
\end{aligned}
$$

Previous literature indicates that work has been done in understanding air flow over different buildings to quantify a mounting position for a small-scale wind turbine. CFD has been employed to further in understanding the wind flow over buildings. The power generation of wind turbines have also been considered with respect to their coefficient of power known as the Betz limit. Although existing literature discusses flow over buildings, simulated models are shown without an existing wind turbine on the roofs. Understanding the simulated flow acting on the small wind turbine can help in quantifying the velocity distribution on the blades. Validating a tool used by many can further quantify their effectiveness in the required area of study. Comparing the two turbulence models which are the realisable $k-\varepsilon$ and the SST $k-\omega$ can provide an understanding of the difference they may share between themselves. They can be used to compare each other's velocity and profiles for the simulated models. Extracting power values from the simulated flows can complement the acquired velocity values. Simulating a sample wind turbine in the ambient condition can help in calculating the power that is available. Cross-referencing that model with the available power curve data of the wind turbine can quantify the extracted power which considers both mechanical and electrical losses.

\section{Physical domain}

The research is based around nine mounting positions of the chosen small-scale roof mounted wind turbine. The small-scale wind turbine will be mounted on proposed building of dimensions $20 \mathrm{~m}$ by $15 \mathrm{~m}$ by $6 \mathrm{~m}$. Figure 1 shows the total of nine positions which are proposed for mounting the wind turbine on the roof of the building. Four corner mounting positions; four edge mounting positions and one mounting position in the center of the building were 


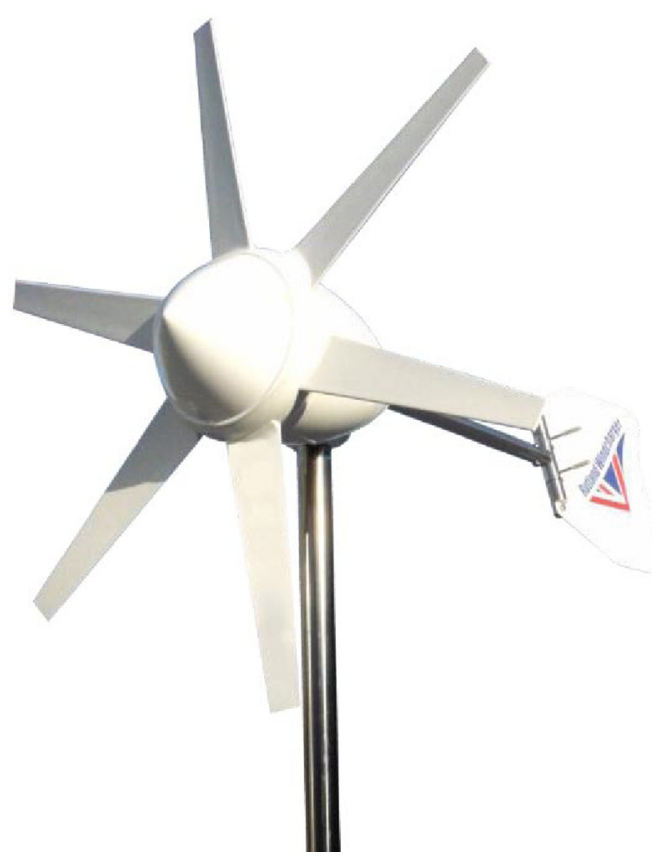

a

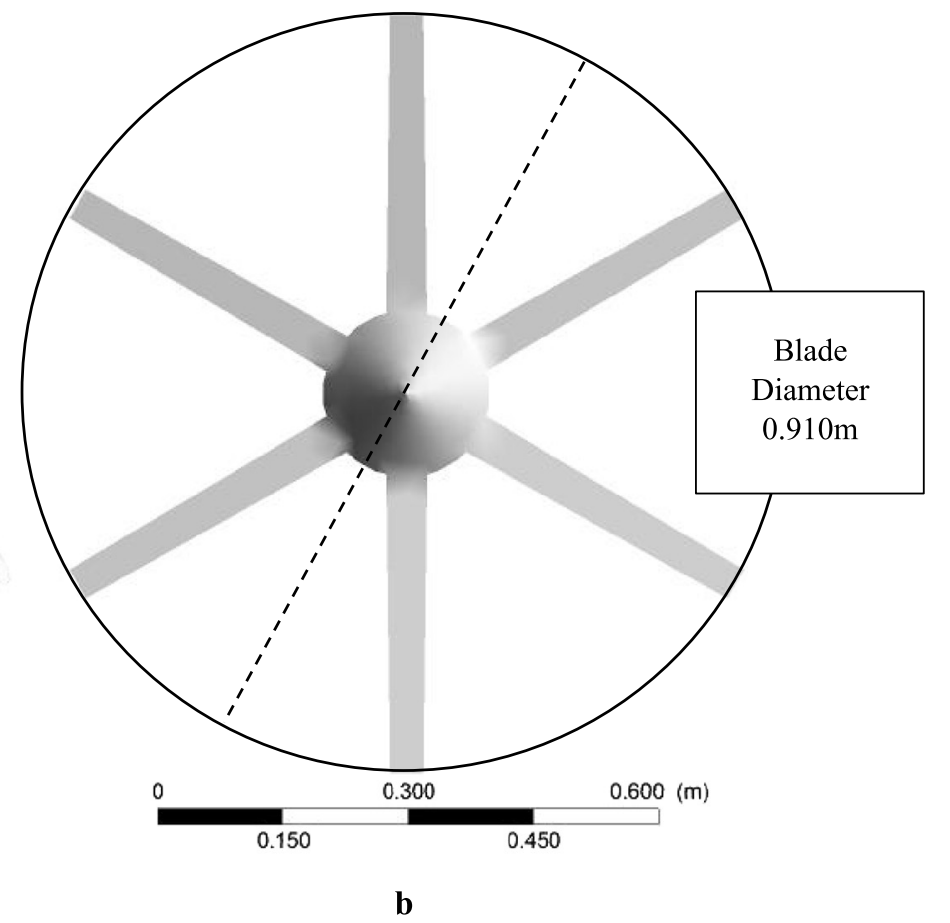

b

Fig. 2. (a) Rautland windcharger FM 910-4 [7]; (b) Rutland windcharger model.

modeled in ANSYS DesignModeler. The stream distance between each mounting position is $9.5 \mathrm{~m}$ and the span distance is $7 \mathrm{~m}$. The control volume incorporated for the models has a volume of $112500 \mathrm{~m}^{3}$.

\subsection{Rutland FM910-4 windcharger}

The wind turbine chosen for this experiment is The Rutland FM910-4 Furlmatic Windcharger [7]. The wind turbine is rated at $155 \mathrm{~W}$ at wind velocity of $15 \mathrm{~m} / \mathrm{s}$. The height of mounting the wind turbine above the building's roof is taken as $2 \mathrm{~m}$. The model of the wind turbine was made in ANSYS Design Modeler. Figure 2a shows the Rutland Wind Charger's design as whole with the nacelle, blades, tail and vane. The wind turbine has a blade diameter of $0.910 \mathrm{~m}$ with a cut in wind speed of $3 \mathrm{~m} / \mathrm{s}$. Figure $2 \mathrm{~b}$ shows the wind turbine model made in ANSYS Design Modeler. The blades and nacelle of the model have been made to close approximation of the original wind turbine.

\section{Computational domain}

Computation Fluid Dynamics (CFD) is the methodology being adopted for simulating the air flow around the building. The computer software being used is ANSYS 17.2 which can simulate the required model parameters. Two turbulence models were simulated on the nine investigated configurations.

\subsection{CFD setup}

Variety of computer based software exist to assess flows across buildings. ANSYS 17.2 was chosen for conducting the computational fluid dynamic simulations for this experiment. Conducting the CFD simulations requires a specific turbulence model inputted in the boundary conditions of ANSYS Fluent. Two types of turbulence models were used to compare results in simulations. Both turbulence models are two-equation models in which the turbulence kinetic energy along with turbulence dissipation or the specific turbulence dissipation rate can be found.

The first turbulence model was the realisable $k-\varepsilon$ which is the most commonly applied in building flow simulations [3]. In this turbulence model, the value $(k)$ represents the turbulence kinetic energy available and the value $(\varepsilon)$ represents the turbulence dissipation. The realisable $k-\varepsilon$ turbulence model was applied to compute the CFD simulations for the experiment. This type of turbulence model was chosen as it is a preferable method to for evaluating flows around an isolated building. This turbulence model predicts the turbulence dissipation rate better than its counter parts. The realisable $k$ - $\varepsilon$ turbulence model has been validated experimentally especially for free flows. The realisable $k$ - $\varepsilon$ turbulence model is composed of Equations (7) and (8). Equation (7) is used for calculating the turbulence kinetic energy $(k)$. Equation $(8)$ is used for calculating the turbulence dissipation rate $(\varepsilon)$ [8].

$$
\begin{aligned}
\frac{\partial}{\partial t}(\rho k)+\frac{\partial}{\partial x_{j}}\left(\rho k u_{j}\right) & =\frac{\partial}{\partial x_{j}}\left[\left(\mu+\frac{\mu_{t}}{\sigma_{k}}\right)+\frac{\partial k}{\partial x_{j}}\right]+P_{k} \\
& +P_{b}-\rho-Y_{M}+S_{k} \\
\frac{\partial}{\partial t}(\rho)+\frac{\partial}{\partial x_{j}}\left(\rho u_{j}\right)= & \frac{\partial}{\partial x_{j}}\left[\left(\mu+\frac{\mu_{t}}{\sigma}\right)+\frac{\partial}{\partial x_{j}}\right]+\rho C_{1} S \\
& -\rho C_{2} \frac{2}{k+\sqrt{v}}+C_{1} \frac{C_{3} P_{b}+S}{k}
\end{aligned}
$$


The second turbulence model was the SST $k-\omega$ which is becoming more popular for building flow simulations. In this turbulence model, the value $(k)$ represents the turbulence kinetic energy available and the value $(\omega)$ represents the specific turbulence dissipation rate. The SST $k$ - $\omega$ turbulence model was chosen since it does not overpredict the eddy viscosity in separated flow simulations. This turbulence model exhibits less sensitivity to free stream conditions than other turbulence models. The SST limiter allows the turbulence model to avoid turbulence kinetic energy build up near stagnation points. The SST $k$ $\omega$ turbulence model is merited for its adequate performance in separating flow and adverse pressure gradients. The turbulence model is composed of Equations (11) and (12). Equation (11) is used to calculate the turbulence kinetic energy $(k)$. Equation (12) is used to calculate the specific turbulence dissipation rate $(\omega)$ [9].

$$
\begin{aligned}
\frac{\partial k}{\partial t}+U_{j} \frac{\partial k}{\partial x_{j}} & =P_{k}-\beta^{*} k \omega+\frac{\partial}{\partial x_{j}}\left[\left(u+\sigma_{k} v_{T}\right) \frac{\partial k}{\partial x_{j}}\right] \\
\frac{\partial \omega}{\partial t}+U_{j} \frac{\partial \omega}{\partial x_{j}} & =\alpha S^{2}-\beta^{*} k \omega+\frac{\partial}{\partial x_{j}}\left[\left(u+\sigma_{k} v_{T}\right) \frac{\partial \omega}{\partial x_{j}}\right] \\
& +2\left(1-F_{1}\right) \sigma_{\omega 2} \frac{1}{\omega} \frac{\partial k}{\partial x_{i}} \frac{\partial \omega}{\partial x_{i}}
\end{aligned}
$$

\subsection{Meshing parameters}

The mesh chosen for this experiment was a fine unstructured tetrahedron for all models with high resolution near the wind turbine. This type of mesh was applied due to flexibility in application to different geometries. This mesh type was also used in several other studies which simulated wind flow $[10,11]$. All models simulated had approximately 310000 elements and 460000 nodes with a growth rate of 1.2. Figure 3 a shows the domains generated mesh with it being finer in the middle near the wind turbine. Figure 3b show the mesh generation going from coarse to fine at the wind turbine. Figure $3 \mathrm{c}$ also shows the mesh detail across a plane intersecting from the middle of the wind turbine. The mesh is seen to be going from coarse to fine where the turbine is located.

\subsection{Grid verification}

Grid adaptation was also used to compute the stability of the CFD models being tested. The verification was done for five different configurations of mesh element cells. A comparison was then made of the computed average velocities and turbulent kinetic energy for all the different meshed cases. The two variables were measured along a linear line $(120 \mathrm{~m})$ starting from the control volume's inlet and across the middle of the wind turbine's nacelle until the outlet. The average values were measured of the velocity and turbulent kinetic energy on the assumed straight line flowing across the control volume. The combined average of the measured values was taken. Figure 4 a shows the posterior error of the measured variables. The error is shown to be maximum for both variables at the second stage of grid adaptation. The posterior error decreases as the number of cells increases displaying that the model eventually stabilises throughout grid adaptation. Figure 4b shows the consistency of the measured physical variables demonstrating that the CFD model simulated were stable in grid adaptation.

\subsection{Boundary conditions}

The inlet wind velocity was set as $4 \mathrm{~m} / \mathrm{s}$ which is average wind speed in the United Arab Emirates region [12]. The default turbulence percentage intensity for the inlet was $5 \%$ with the turbulence viscosity ratio as 10 . The macro fluid volume was also used to simulate the external flow conditions of the environment by using gravity. The wind flow was simulated at 0 degrees of the main axis in which the models were set.

A total of eighteen models were simulated using two different types of turbulence models. For one set of nine models, the realisable $k-\varepsilon$ turbulence model with standard wall functions was applied. The realisable $k$ - $\varepsilon$ turbulence model constraints were kept as default. The second set of nine models was simulated using the SST $k-\omega$ turbulence model with the production limiter turned on. The SST $k-\omega$ turbulence model constraints were also kept as default. Table 1 shows the summary of the various boundary conditions applied to run the models.

\section{Results and discussion}

CFD simulations produced results similar to those analysed in existing literature. The nine existing models have been examined based on their velocity flow profiles. The velocity profiles of each model described the air flow pattern across the building and the wind turbine. Velocity graphs across the nacelle of the wind turbine in the enclosed model have been further discussed too. The velocity graphs across the nacelle helped in understanding changes in wind speed of each model. Augmentation percentages of the initial wind speed increase are also discussed to analyse which wind turbine model generated the maximum velocity. The difference between turbulence models is discussed to conclude which of the two-selected produced the most realistic results. Lastly, the power generated by the chosen wind turbine is discussed to analyse the effect of velocity.

\subsection{Velocity profiles}

Wind speed acceleration is the central focus around this study. The acceleration of wind velocity above the building roof provides the required power for the wind turbine to operate and produce energy. A total of nine wind turbines mounting positions were selected. The wind turbines mounting positions will be discussed in the groups. Stream acceleration is the accelerated wind speed above the building will be discussed as it will be shown in the velocity profiles of all models. The separation bubble is the area 


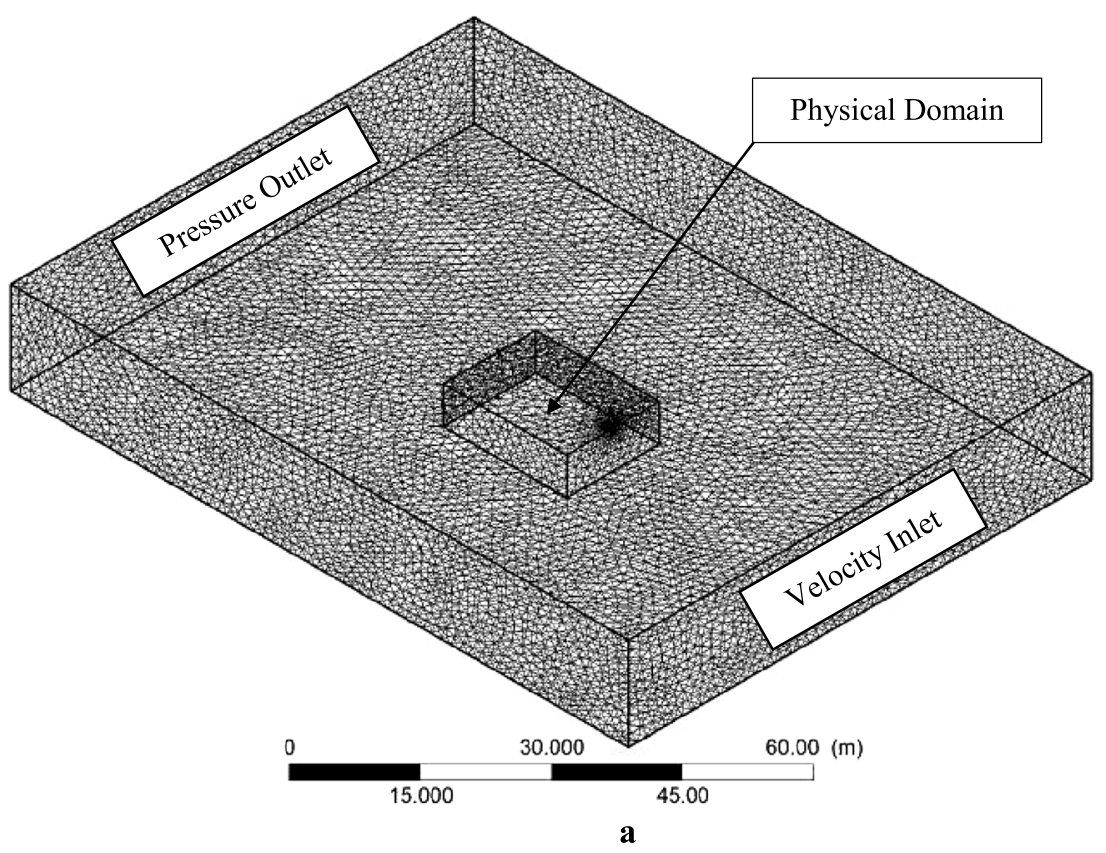

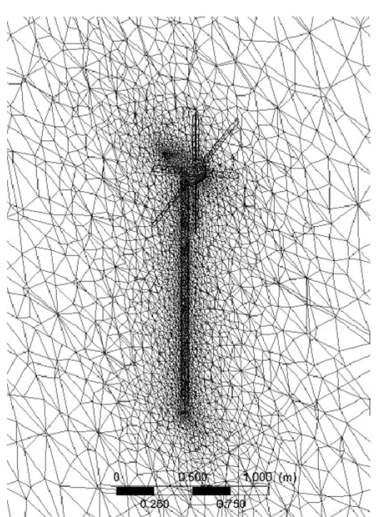

b

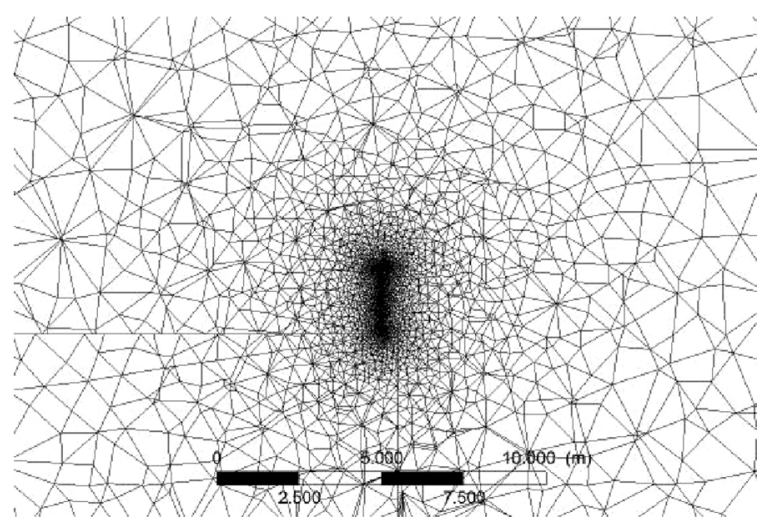

c

Fig. 3. (a) Domains mesh; (b) Meshed wind turbine; (c) Mesh transformation across a plane.

\section{- - - Average Turbulence Kinetic Energy (J/kg)}

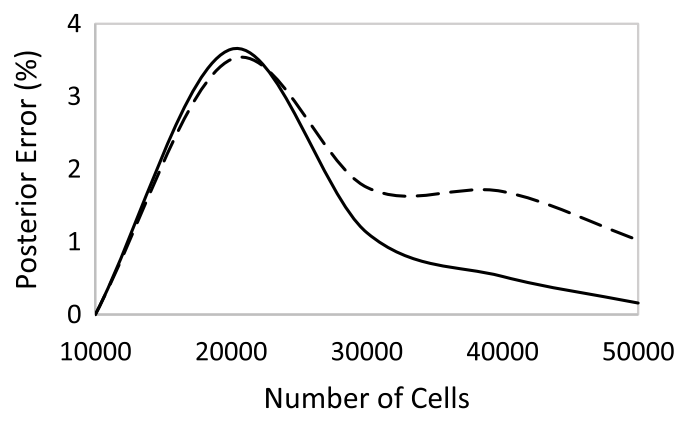

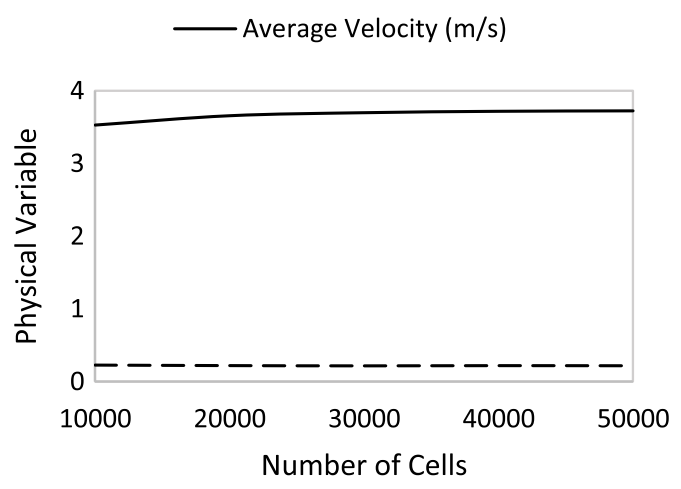

b

Fig. 4. (a) Error with rising cell count; (b) Variables with rising cell count. 
Table 1. Boundary conditions applied for model Simulations.

\begin{tabular}{ll}
\hline Parameter & Description/Value \\
\hline Air inlet velocity & $4 \mathrm{~m} / \mathrm{s}$ \\
Time & Steady-State \\
Turbulence models & Realisable $k$ - $\varepsilon$ SST $k-\omega$ \\
Wind direction & $0^{\circ}$ from the main axis of the models \\
Gravity & $-9.81 \mathrm{~m} / \mathrm{s}^{-2}(Y$-axis direction) \\
Spatial discretisation & Second-order upwind \\
Discretisation method & Finite volume \\
\hline
\end{tabular}

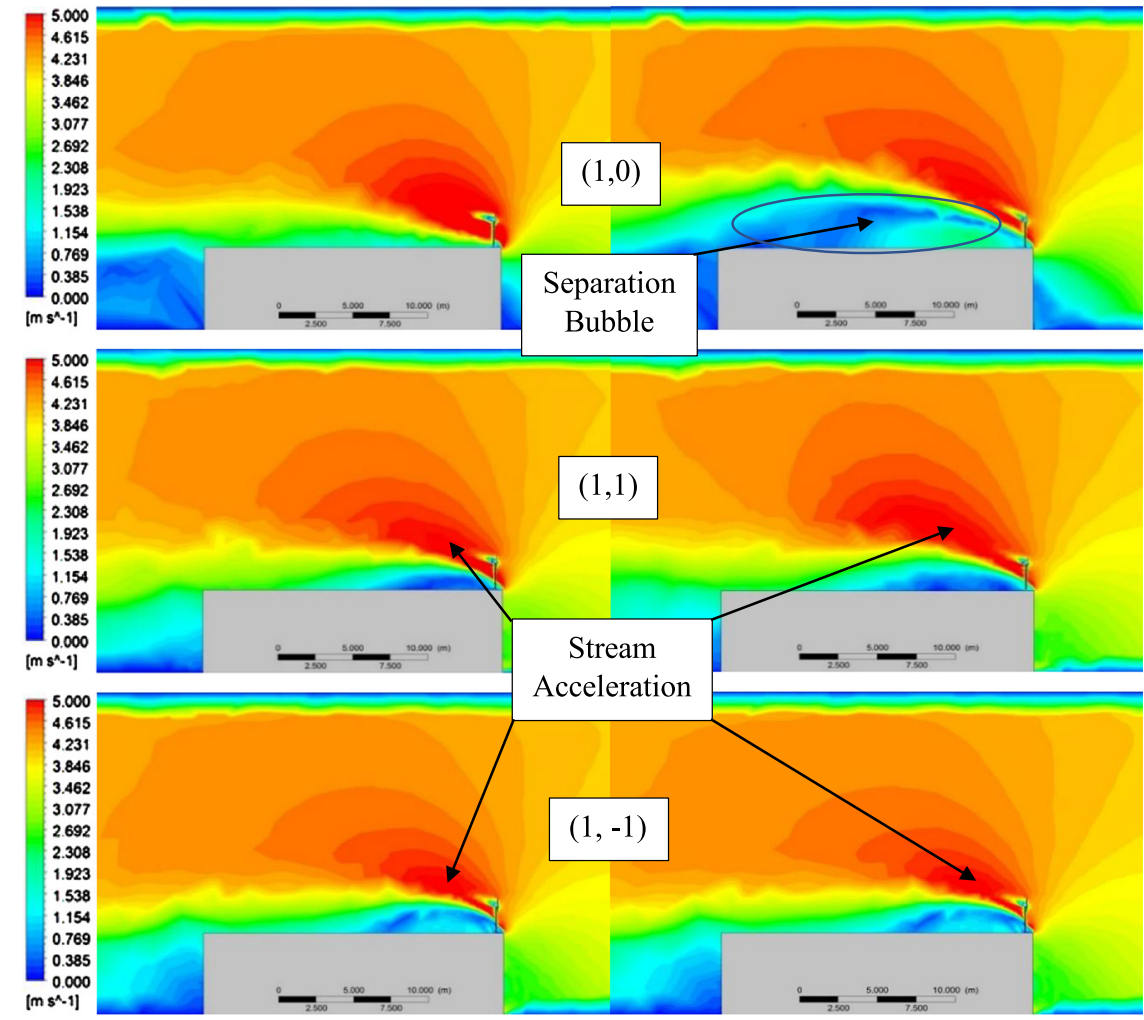

Fig. 5. Windward three mounting positions $k-\varepsilon$ (Left) and $k-\omega$ (Right).

where turbulence is at its highest and the wind speed is at the lowest will also be discussed in the velocity profiles. The windward set of three will be discussed first; followed by the center three and then the leeward three. The velocity profiles are compared between the results of the selected two turbulence models.

The windward three wind turbines mounting positions are the $(1,1),(1,0)$ and $(1,-1)$ respectively. The velocity profiles of the all three positions are shown in Figure 5 . The profiles are arranged to show a direct comparison in the wind velocity difference between the $k-\varepsilon$ (left) and $k-\omega$ (right) turbulence model. The top two velocity profiles are of the mounting position $(1,0)$ respectively. The center two velocity profiles are of the mounting positions $(1,1)$ respectively. The bottom two velocity profiles are of the mounting positions $(1,-1)$ respectively. The $k-\varepsilon$ velocity profile of the mounting position $(1,0)$ produced a larger domain of stream acceleration than the alternative $k-\omega$. The $k-\varepsilon$ velocity profile did not produce a separation bubble contrary to the analysed literature. The $k-\omega$ velocity profile produced a different wind pattern than the $k-\varepsilon$ velocity profile. The domain of the stream velocity acceleration in the $k-\omega$ model was slightly lower than that observed in the $k-\varepsilon$ profile. The $k-\omega$ did produce the separation bubble that was seen in the existing literature. The mounting position $(1,1)$ produced similar velocity flow patterns in both turbulence models with the stream acceleration and separation bubble. The only difference between the two was stream acceleration was observed to be more in the $k-\omega$ rather than the $k$ - $\varepsilon$ model. The mounting position $(1,-1)$ produced identical velocity wind flow profiles. The stream acceleration along with the separation bubble had identical flow characteristics in both selected turbulence models. 


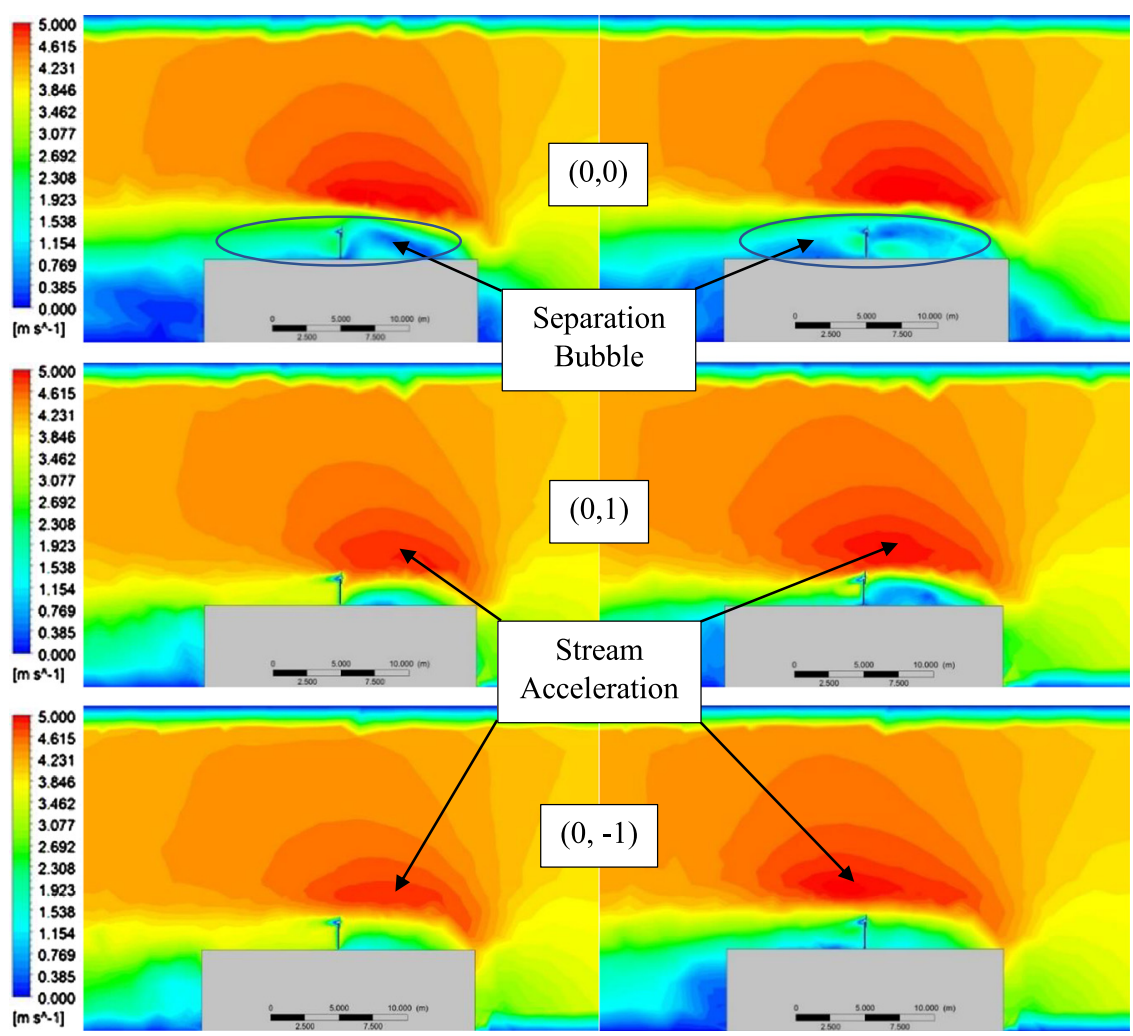

Fig. 6. Center three mounting positions $k-\varepsilon$ (Left) and $k-\omega$ (Right).

The center three wind turbines mounting positions are the $(0,1),(0,0)$ and $(0,-1)$ respectively. The velocity profiles of the all three central positions are shown in Figure 6. The profiles are arranged to show a direct comparison in the wind velocity difference between the $k-\varepsilon$ (left) and $k-\omega$ (right) turbulence model. The top two velocity profiles are of the mounting position $(0,0)$ respectively. The center two velocity profiles are of the mounting positions $(0,1)$ respectively. The bottom two velocity profiles are of the mounting positions $(0,-1)$ respectively. The $k-\varepsilon$ and $k-\omega$ velocity profiles of the mounting position $(0,0)$ produced similar results. Both have shown identical areas of the stream acceleration occurring above and before the roofmounted wind turbine. The stream velocity is shown to be occurring at twice the recommended pole height of the wind turbine. The separation bubble is present before the mounted wind turbine in both velocity profiles. The mounting position $(0,1)$ produced similar velocity flow patterns in both turbulence models with the stream acceleration and separation bubble. The $k-\varepsilon$ predicted a slightly lower concentration of stream acceleration than that observed in the $k-\omega$. The concentration of the separation bubble in the $k-\varepsilon$ velocity profile was lesser than the $k-\omega$. The mounting position $(0,-1)$ produced different velocity wind flow profiles. The stream acceleration in the $k-\varepsilon$ velocity profile was slightly lower and occurred before the mounting position of the wind turbine. The stream acceleration in the $k-\varepsilon$ was larger directly above the wind turbine.

The leeward three wind turbines mounting positions are the $(-1,1),(-1,0)$ and $(-1,-1)$ respectively. The velocity profiles of the all three positions are shown in Figure 7 . The profiles are arranged to show a direct comparison in the wind velocity difference between the $k-\varepsilon$ (left) and $k-\omega$ (right) turbulence model. The top two velocity profiles are of the mounting position $(-1,0)$ respectively. The center two velocity profiles are of the mounting positions $(-1,0)$ respectively. The bottom two velocity profiles are of the mounting positions $(-1,0)$ respectively. The mounting position $(-1,0)$ of the wind turbine produced an identical result of the stream acceleration and the separation bubble. The stream acceleration was shown to be occurring above and well before the mounted position of the wind turbine. The separation bubble of the velocity profiles remained constant on top of the roof. The mounting positions $(-1,1)$ and $(-1,-1)$ variation profiles produced identical wind flow patterns with stream acceleration occurring well before the wind turbines position. The separation bubble across these models was noticeably lesser than the middle-rear wind turbine positions. This would be due to the mounting positions being at the building's edges hence the separation bubble had a lesser influence on the velocity profiles. The $k-\varepsilon$ velocity profile did not produce a separation bubble contrary to the analyzed literature.

\subsection{Velocity trends}

Understanding velocity acceleration occurring near the wind turbine and at the top of the building will help in establishing which mounting position is the most well suited. The wind speeds were taken across a line passing from the beginning of the control volume, through the middle of the wind turbine's nacelle and until the end of the 


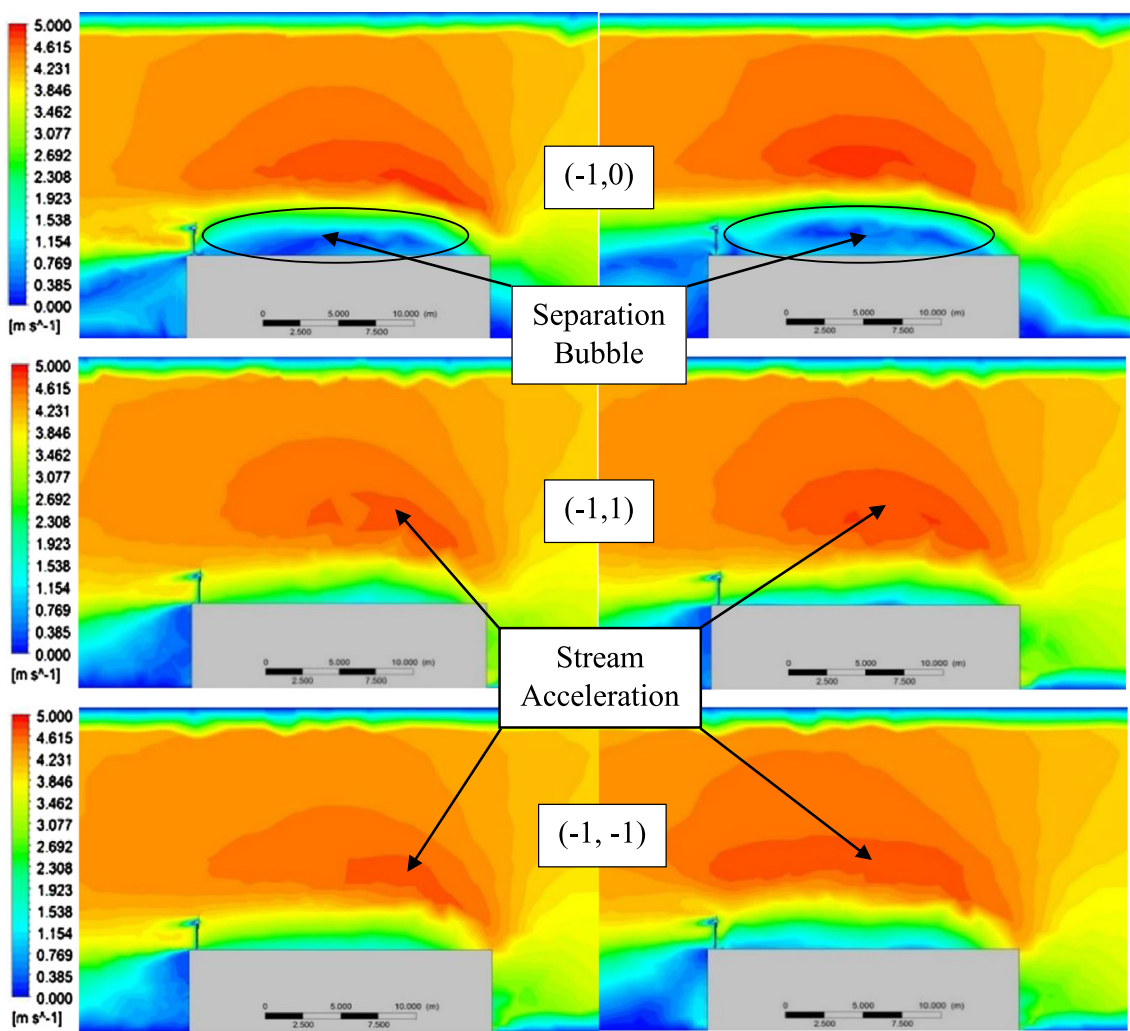

Fig. 7. Leeward three mounting positions $k-\varepsilon$ (Left) and $k-\omega$ (Right).

control volume. A total of fifty velocity samples were taken from the imaginary line passing through the wind turbine's nacelle. These samples will be represented in plot graphs shown in Figure 8 for comparison of the wind velocity trends occurring in all models. Further group analysis is done of these plot graphs with respect to their mounting positions and turbulence models.

Figure 8 represents two plot graphs displaying the velocity trends occurring throughout the control volume of the model. The first set of velocity trends are of the windward mounting positions of the wind turbines. The windward mounting positions consist of $(1,1),(1,0)$ and $(1,-1)$. The dotted bluelineintersecting the graph at axial length $45.5 \mathrm{~m}$ is the mounting location of the wind turbine. The second set of velocity trends are of the center mounting positions of the wind turbines. The center mounting positions consist of $(0,1)$, $(0,0)$ and $(0,-1)$. The dotted black line intersecting the graph at axial length $55 \mathrm{~m}$ is the mounting location of the wind turbine. The third and final set of velocity trends are of the leeward mounting positions of the wind turbines. Theleeward mounting positions consist of $(-1,1),(-1,0)$ and $(-1,-1)$. The dotted orange line intersecting the graph at axial length $64.5 \mathrm{~m}$ is the mounting location of the wind turbine. The maximum velocities observed at all nine mounting locations of the small-scale wind turbine are shown in Table 2.

\subsection{Augmentation factor}

The increase in wind velocity determines the amount of augmentation achieved by a model. Augmentation percentages are based on the maximum achieved value divided by the initial inputted value. Each model simulated had an inputted inlet velocity of $4 \mathrm{~m} / \mathrm{s}$ [12]. The increase in wind speed at the required mounting position will give an augmentation percentage. The percentages were only applicable to the front wind turbine mounting positions. This was due to the maximum wind speed being achieved at the wind turbines mounting location itself. Table 2 shows the maximum amount of augmentation achieved for the six simulated models. The maximum augmentation achieved was by the $(1,0) k-\omega$ model at $33 \%$. The lowest augmentation achieved was by the $(1,-1) k-\omega$ model at $26.5 \%$.

The maximum augmentation was achieved from both turbulence models mounted at the $(1,0)$ central-windward location. The maximum augmentation was produced by the $k-\omega(1,0)$ which was $33 \%$. The augmentation produced by the $k-\varepsilon(1,0)$ model was $29.75 \%$ which is $3.25 \%$ lesser than the $k-\omega$ model. Figure 9 shows the two turbulence models distribution of wind velocity on the turbine blades. The $k-\varepsilon$ model shows the wind turbine blades are getting a larger velocity compared to the $k-\omega$ model. The SST $k-\omega$ turbulence model was effective in procuring the maximum velocity at a specific point as well as providing the same speed distribution at the wind turbine blades. The realizable $k-\varepsilon$ turbulence model also was effective in procuring maximum velocity at a specific point and producing a slightly better acceleration effect on the wind turbine blades than the SST $k-\omega$ turbulence model. The maximum augmentation produced by the $k-\varepsilon(1,1)$ which was $29.25 \%$. The augmentation produced by the $k-\omega(1,1)$ model was $27.25 \%$ which is $2 \%$ lesser than the $k$ - $\varepsilon$ model. 

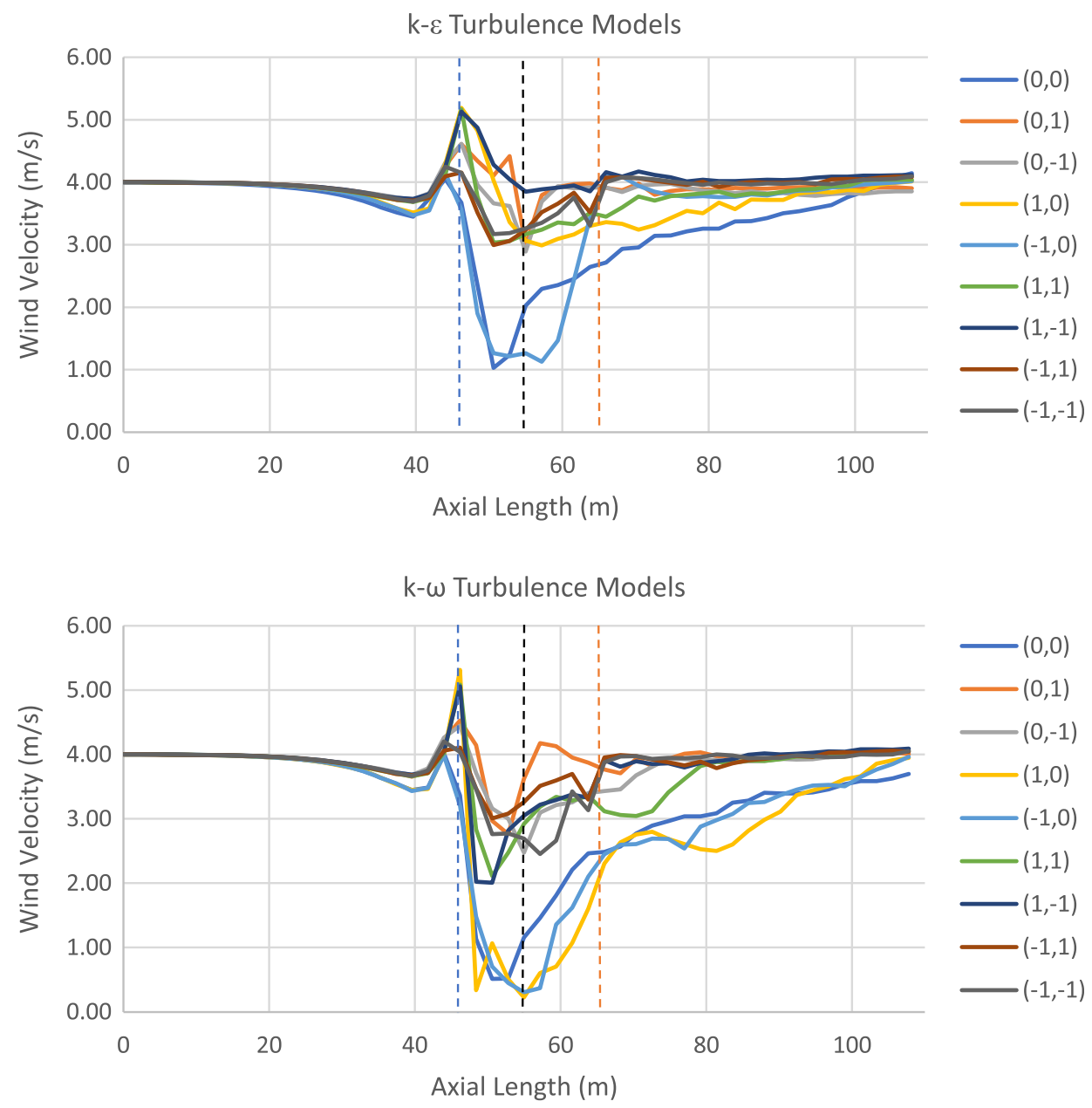

Fig. 8. Wind velocity trends of $k-\varepsilon$ and $k-\omega$ turbulence models.

Table 2. Maximum velocities observed at the wind turbine positions.

\begin{tabular}{rlrl}
\hline $\begin{array}{l}k-\varepsilon \text { Model } \\
\text { position }\end{array}$ & Max. velocity $(\mathrm{m} / \mathrm{s})$ & $\begin{array}{l}k \text { - } \omega \text { Model } \\
\text { position }\end{array}$ & Max. velocity $(\mathrm{m} / \mathrm{s})$ \\
\hline$(1,1)$ & 5.17 & $(1,1)$ & 5.09 \\
$(1,0)$ & 5.19 & $(1,0)$ & 5.32 \\
$(1,-1)$ & 5.13 & $(1,-1)$ & 5.06 \\
$(0,1)$ & 2.99 & $(0,1)$ & 3.62 \\
$(0,0)$ & 2.02 & $(0,-1)$ & 1.16 \\
$(0,-1)$ & 2.89 & $(-1,1)$ & 2.47 \\
$(-1,1)$ & 3.52 & $(-1,0)$ & 3.3 \\
$(-1,0)$ & 3.43 & $(-1,-1)$ & 2.1 \\
$(-1,-1)$ & 3.31 & & 3.13 \\
\hline
\end{tabular}

Both turbulence models show an identical velocity distribution on the wind turbine blades. Hence both turbulence models were consistent in producing the same result of velocity distribution on the wind turbine blades for the $(1,1)$ mounting location. The maximum augmentation produced by the $k-\varepsilon(1,-1)$ which was $28.25 \%$. The augmentation produced by the $k-\omega(1,-1)$ model was $26.5 \%$ which is $1.75 \%$ lesser than the $k-\varepsilon$ model. Both turbulence models showed a similar velocity distribution on the wind turbine blades. The $k-\varepsilon$ model had a slightly higher velocity on the wind turbine blades than the $k-\omega$ model. Table 3 

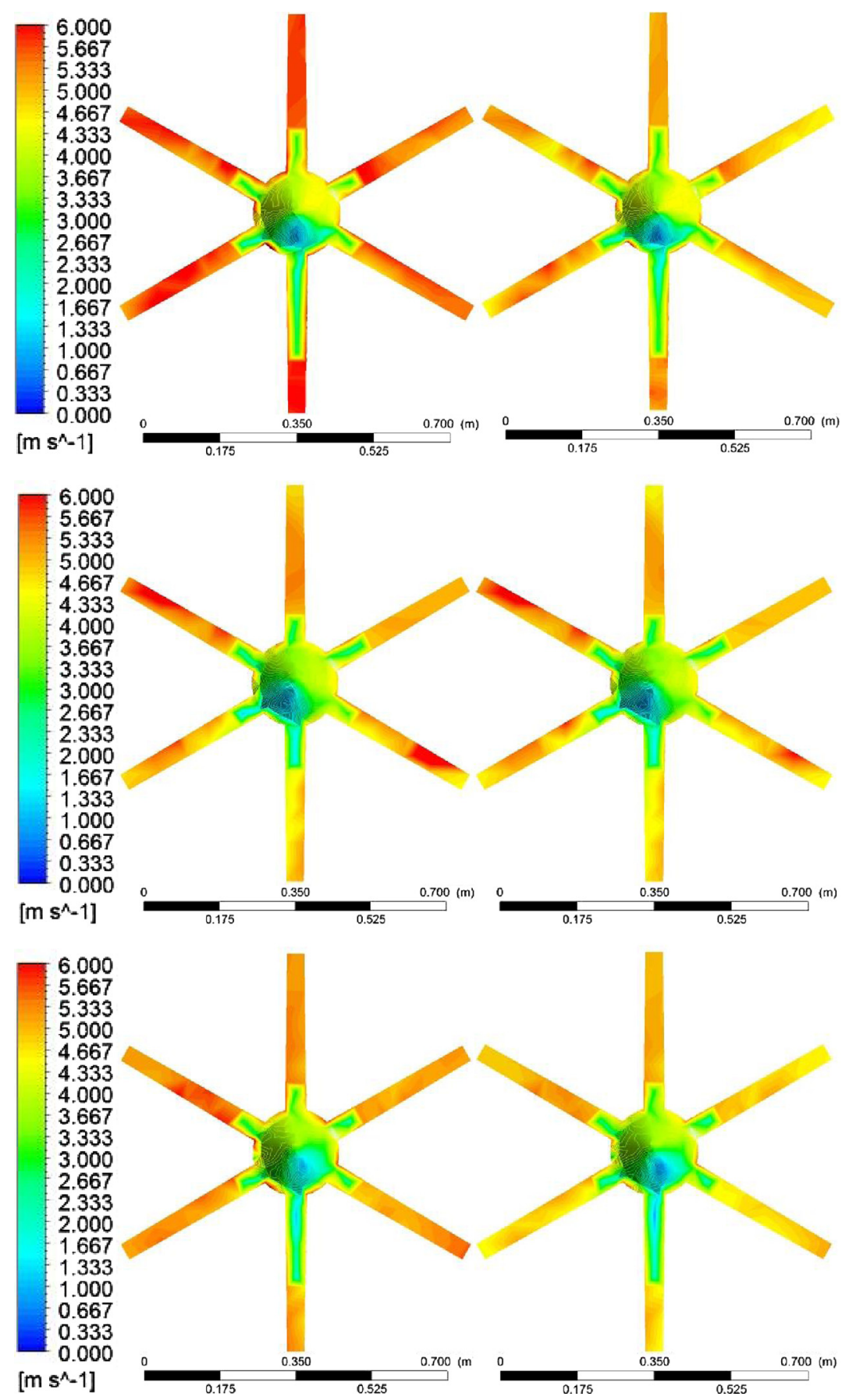

Fig. 9. $k-\varepsilon$ (Left) and $k-\omega$ (Right) $(1,0)$ Model velocity distribution on wind turbine blades.

Table 3. Augmentation percentages of $k-\varepsilon$ and $k-\omega$ turbulence models.

\begin{tabular}{llll}
\hline Models & Inlet speed $(\mathrm{m} / \mathrm{s})$ & Max. speed $(\mathrm{m} / \mathrm{s})$ & Augmentation $(\%)$ \\
\hline$(1,1) k-\varepsilon$ & & 5.17 & 29.2 \\
$(1,0) k-\varepsilon$ & & 5.19 & 29.8 \\
$(1,-1) k-\varepsilon$ & 4 & 5.13 & 28.3 \\
$(1,1) k-\omega$ & & 5.09 & 27.3 \\
$(1,0) k-\omega$ & 5.32 & 33.0 \\
$(1,-1) k-\omega$ & & 5.06 & 26.5 \\
\hline
\end{tabular}




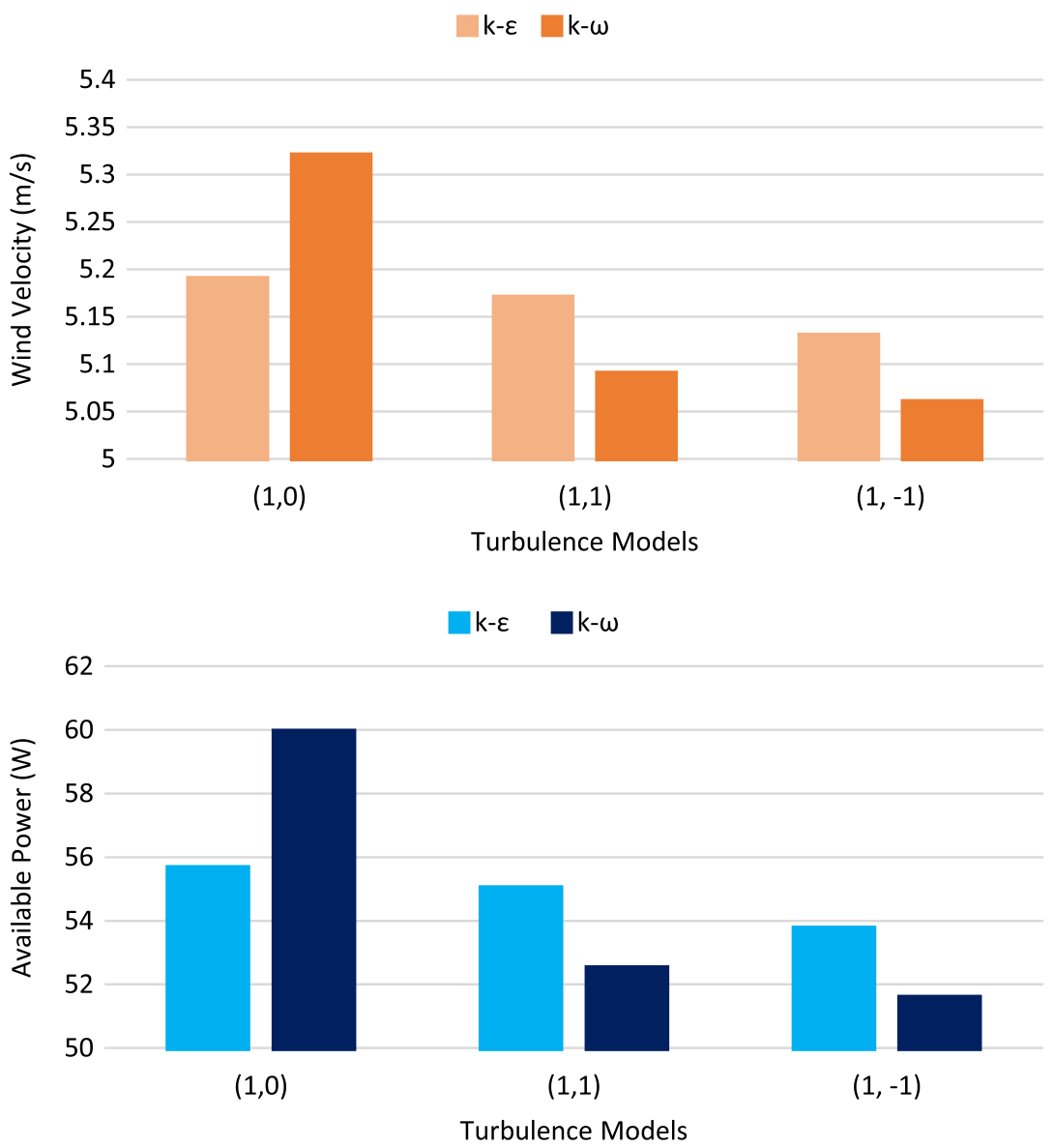

Fig. 10. Windward models available power and peak velocities.

\subsection{Power extraction}

Power generated from a wind turbine is dependent on several factors. These include the available energy from the wind velocity and the wind turbine's blade cross-sectional area. Using Equation (1), the available power can be determined with the density of air, wind turbine's blade cross-sectional area and the wind velocity. The crosssectional blade area of The Rutland FM910-4 Furlmatic Windcharger is $0.65 \mathrm{~m}^{2}$. The incoming wind velocity for each model is taken from the augmentation Table 2. The density of air is taken as $1.225 \mathrm{~kg} / \mathrm{m} 3$. Figure 10 gives a summary of the velocity along with the maximum available power for the wind turbine.

\subsection{The Rutland FM910-4 power curve}

The power curve of a wind turbine determines the amount of power it can produce with the available wind speed. The Rutland FM910-4 power curve is given in the Figure 11. The power curve is shows the initial cut-in wind speed to be $3 \mathrm{~m} / \mathrm{s}$. The power to speed ratio steadily rises until $16 \mathrm{~m} / \mathrm{s}$ where the wind turbine reaches a maximum output of $160 \mathrm{~W}$. Wind turbines are manufactured with specific rated power at the prescribed wind speed.

Wind turbines are not able to extract the full amount of power that is available in the wind speed. The total available power tends to be different than the total extractable power by the wind turbine. The difference between the two is that the total extractable power adds another variable to the equation which is a coefficient of performance. This coefficient of performance is known as the Betz limit. The Betz limit is known to be the maximum power output that can be achieved by a wind turbine which is $59.3 \%$. The air passing through at speed spreads outwards and loses its kinetic energy as it is extracted by the wind turbine. The limit is set at $59.3 \%$ as the geometry constraints the efficiency from going higher. Interpolating the acquired wind speeds from the CFD models into the Rutland FM910-4 power curve gives the extracted power by the wind turbine. Modifying the equation to acquire the coefficient of power, the extracted power by the wind turbine is divided by the total available wind power. Equation (11) is a modified version of Equation (1) with the addition of the Coefficient of Power (Cp) variable.

$$
P=C_{p} \frac{\rho A u^{3}}{2}
$$

The Betz limit for the Rutland FM910-4 is $38.2 \%$. Figure 12 shows the total extractable power by the Rutland FM910-4 within the wind turbine's power curve. The maximum extracted wind power is achieved by the $(1,0) k$ $\omega$ model which is $22.84 \mathrm{~W}$. The minimum extracted wind power is achieved by the $(1,-1) k$ - $\omega$ model which is 


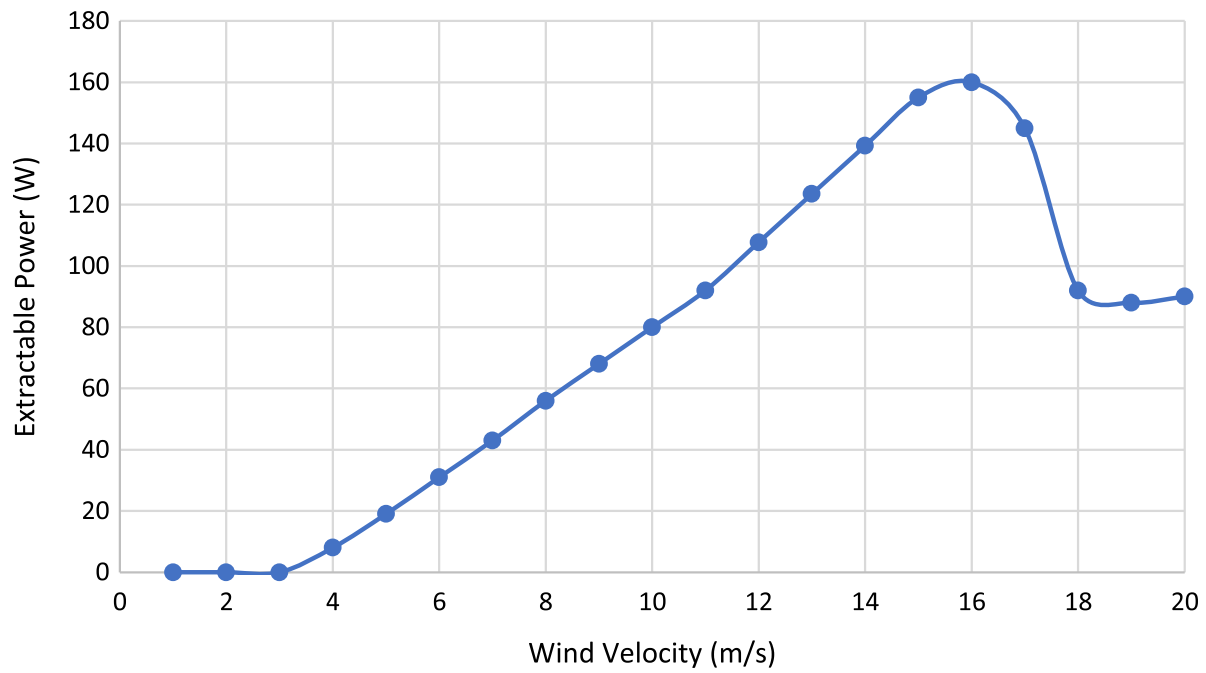

Fig. 11. The Rutland FM910-4 windcharger's power curve [7].
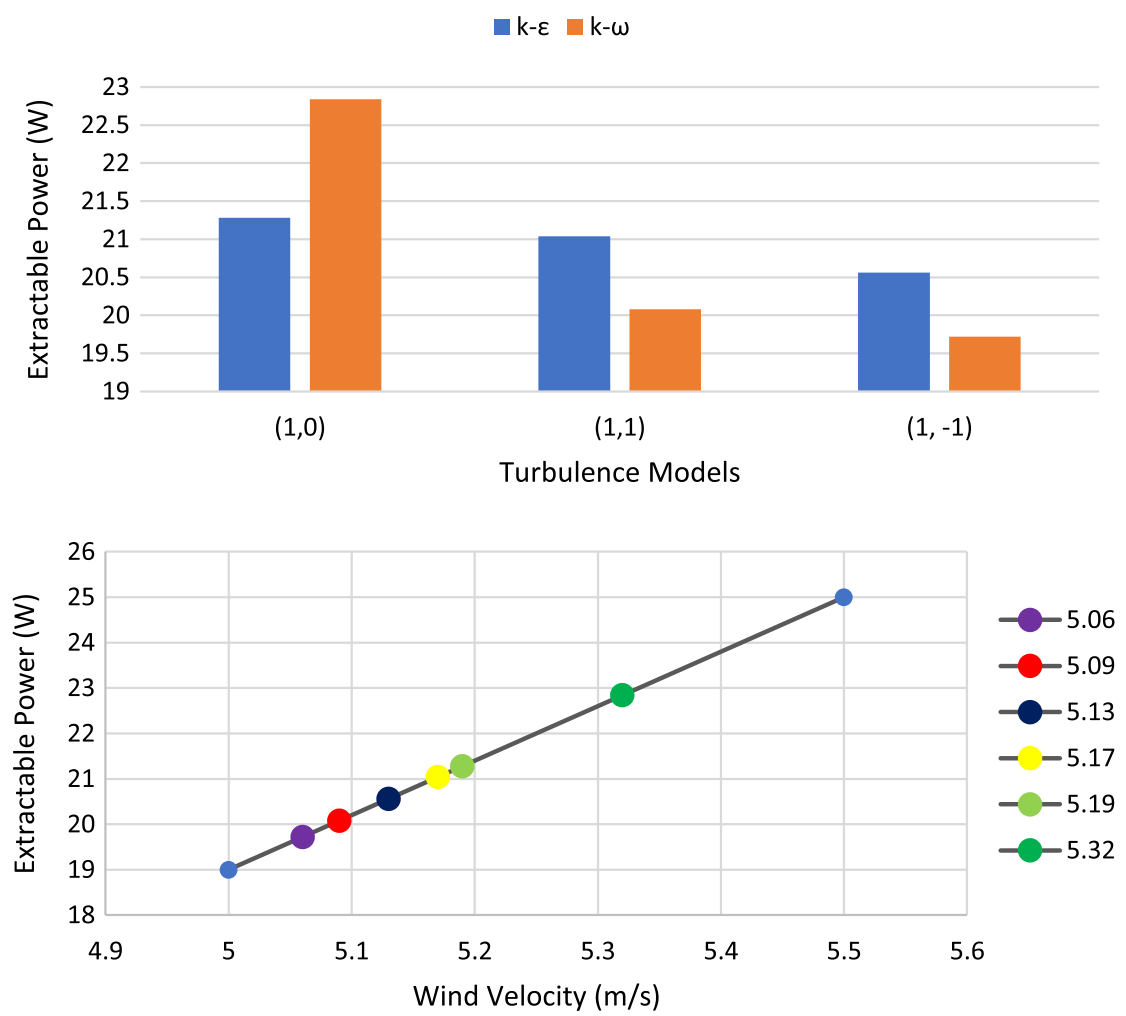

Fig. 12. Extractable power from windward models.

19.72 W. The trend of power extraction by the wind turbine is shown to be consistent with both turbulence models. The central-upwind wind turbine in both models produces the most power. The corner windward turbines produce lesser power in contrast to the central-upwind wind turbine.

\section{Conclusion}

This paper determined the optimum sitting of a small-scale roof-mounted wind turbine. Following the CFD analyses, the ideal mounting position for the small wind turbine was established to be the location $(1,0)$. This location has been validated by both the realisable $k-\varepsilon$ and SST $k$ - $\omega$ turbulence models to be the most optimum position for wind turbine to extract the maximum power.

Results showed that the operational efficiency of the Rutland 910-4 Windcharger were only possible to achieve in the windward mounting locations where the stream acceleration was higher than the rated wind speed of the wind turbine. Although the stream accelerated wind speeds of the windward models was adequate, it was consistent throughout the three upward positions as it stayed above $5 \mathrm{~m} / \mathrm{s}$. Comparing the two-simulated realisable $k-\varepsilon$ and SST $k-\omega$ turbulence models, both produced results that 
were consistent with one another. However, the variance in wind speeds achieved between the three-wind turbine mounting positions of the realisable $k-\varepsilon$ models was lesser compared to the SST $k-\omega$ models. The $(1,0) k-\omega$ model produced the highest wind velocity which was $5.32 \mathrm{~m} / \mathrm{s}$ with the wind turbine extracting power of $22.84 \mathrm{~W}$. The $(1,-1) k$ - $\omega$ model produce the lowest wind velocity which was $5.06 \mathrm{~m} / \mathrm{s}$ with the wind turbine extracting power of $19.72 \mathrm{~W}$

Small-scale roof mounted wind turbines are one of the future decentralised energy generation methods. Understanding how they can be applied to the urban society would inevitably make them a source of viable means of energy generation. Small-scale roof mounted wind turbines can serve as a small source of power generation if the local topology and weather conditions are considered adequately. Investigating in an urban setting of building configurations with small wind turbines mounted on the roofs or any other viable areas where wind velocity is enough. Modeling different roof shapes which can be used to produce uniform stream acceleration for the wind turbine to utilise. Furthermore, mounting locations for small wind turbines tend to vary in each roof configuration due to the wind velocity and pressure profiles created.

\section{Nomenclature}

\section{Variable Description}

$P \quad$ Wind Power $(\mathrm{W})$

$\rho \quad$ Density $\left(\mathrm{kg} / \mathrm{m}^{3}\right)$

A Cross-sectional area $\left(\mathrm{m}^{2}\right)$

$u \quad$ Velocity $(\mathrm{m} / \mathrm{s})$

$C_{p} \quad$ Coefficient of performance (Betz Limit)

$k \quad$ Specific turbulence kinetic energy $\left(\mathrm{m}^{2} / \mathrm{s}^{2}\right)$

$\varepsilon \quad$ Turbulent dissipation rate $\left(\mathrm{s}^{-1}\right)$

$\omega \quad$ Specific turbulent dissipation rate $\left(\mathrm{s}^{-1}\right)$

$P_{k} \quad$ Rate of production of $k\left(\mathrm{~kg} / \mathrm{ms}^{3}\right)$

$P_{\omega} \quad$ Rate of production of $\omega\left(\mathrm{kg} / \mathrm{m}^{3} \mathrm{~s}^{2}\right)$

$P_{b} \quad$ Turbulent kinetic energy due to buoyancy

$\beta$ * Turbulence modeling constant

$B^{*} \quad$ Turbulence modeling constant

$F_{1} \quad$ Blending function

$G_{k}$ Turbulent kinetic energy due to the average velocity gradient

$G_{b} \quad$ Turbulent kinetic energy due to buoyancy

$Y_{M}$ Fluctuating dilation in compressible turbulence

$Y_{k}$ Dissipation of turbulent kinetic energy due to turbulence

$S_{k} \quad$ User defined constant

$C$ Linear-anisotropic phase function coefficient

$S \quad$ Strain rate magnitude $\left(\mathrm{m}^{-1}\right)$

$D_{\omega} \quad$ Cross diffusion term

$\sigma \quad$ Turbulent Prandtl number
$v_{T} \quad$ Kinematic eddy viscosity $\left(\mathrm{m}^{2} / \mathrm{s}\right)$

Abbreviation Description

CFD Computational Fluid Dynamics

BEM Blade Element Momentum

HAWT Horizontal-Axis Wind Turbine

VAWT Vertical-Axis Wind Turbine

BAWT Building Augmented Wind Turbine

SST Shear Stress Transport

\section{References}

1. A. Tummala, R. Velamati, D. Sinha, V. Indraja, V. Krishna, A review on small scale wind turbines, Renew. Sustain. Energy Rev. 56, 1351 (2016)

2. L. Ledo, P. Kosasih, P. Cooper, Roof mounting site analysis for micro-wind turbines, Renew. Energy 36, 1379 (2011)

3. I. Abohela, N. Hamza, S. Dudek, Effect of roof shape, wind direction, building height and urban configuration on the energy yield and positioning of roof mounted wind turbines, Renew. Energy 50, 1106 (2013)

4. Mertens, The energy yield of roof mounted wind turbines, Wind Eng. 27, 507 (2003)

5. J. Bukala, K. Damaziak, K. Kroszczynski, M. Krzeszowiec, J. Malachowski, Investigation of parameters influencing the efficiency of small wind turbines, J. Wind. Eng. Ind. Aerodyn. 146, 29 (2015)

6. M. Cable, An Evaluation of Turbulence Models for the Numerica l Study of Forced and Natural Convective Flow in Atri a (2009), http://www.collectionscanada.gc.ca/obj/ thesescanada/vol2/OKQ/TC-OKQ-1884.pdf (accessed 6 Apr. 2017)

7. A. Windcharger, Rutland FM910-4 Furlmatic Windcharger - Marlec (2017), https://www.marlec.co.uk/ product/rutland-fm910-4-furlmatic-windcharger/?v= ea8a1a99f6c9 (accessed 6 Apr. 2017)

8. Cfd-online.com, Realisable k-epsilon model-CFD-Wiki, the free CFD reference (2017), https://www.cfd-online. com/Wiki/Realisable k-epsilon model (accessed 6 Apr. 2017)

9. Cfd-online.com, SST k-omega model-CFD-Wiki, the free CFD reference (2017), https://www.cfd-online.com/ Wiki/SST_k-omega_model (accessed 6 Apr. 2017)

10. J. Blazek, Computational fluid dynamics, (ButterworthHeinemann, an imprint of Elsevier, Amsterdam, 2015)

11. H. Chaudhry, B. Hughes, Computational analysis of dynamic architecture, in Proceedings of the Institution of Mechanical Engineers Part A Journal of Power and Energy (2010) pp. 85-95

12. Weatherspark.com, Average Weather For Dubai, United Arab Emirates - WeatherSpark (2017), https://weath erspark.com/averages/32855/Dubai-United-Arab-Emi rates (accessed 6 Apr. 2017) 